Swarthmore College

Works

3-1-2006

\title{
Subjective And Objective Measures Of Governmental Regulations In OECD Nations
}

\author{
G. Nicoletti
}

Frederic L. Pryor

Swarthmore College, fpryor1@swarthmore.edu

Follow this and additional works at: https://works.swarthmore.edu/fac-economics

Part of the Economics Commons

Let us know how access to these works benefits you

\section{Recommended Citation}

G. Nicoletti and Frederic L. Pryor. (2006). "Subjective And Objective Measures Of Governmental Regulations In OECD Nations". Journal Of Economic Behavior And Organization. Volume 59, Issue 3. 433-449. DOI: 10.1016/j.jebo.2004.05.003

https://works.swarthmore.edu/fac-economics/172

This work is brought to you for free by Swarthmore College Libraries' Works. It has been accepted for inclusion in Economics Faculty Works by an authorized administrator of Works. For more information, please contact myworks@swarthmore.edu. 
Revised draft

\title{
SUBJECTIVE AND OBJECTIVE MEASURES OF GOVERNMENTAL REGULATIONS IN OECD NATIONS*
}

\begin{abstract}
In analyzing the performance of market economies, it is useful to include measurements of the extent of government regulation. Constructing such indices, however, raises some difficult methodological issues. After reviewing some of these problems, we compare the results of three recent quantitative studies of regulation in OECD nations, one based on an extensive review and quantification of laws and regulations, the other two based on opinion data of those familiar with these regulations. Despite their very different methodologies and coverage of particular types of governmental regulation, the results of the three studies are significantly correlated which suggests that all three capture an important underlying reality.
\end{abstract}

JEL Classifications: L50, P11, P14, P52 Key words: government regulation, quantitative methods

\author{
Giuseppe Nicoletti \\ OECD Economics Department \\ 2, rue André-Pascal \\ Paris 76015, France \\ Tel. (33) 145248730 \\ Fax (33) 145241347 \\ E-mail: Giuseppe.Nicoletti@oecd.org
}

Frederic L. Pryor

Emeritus Professor of Economics, Swarthmore College

Swarthmore, PA 19081, USA

Telephone: $610-328-8130$

Fax: 610-328-7352

E-mail: fpryor1@swarthmore.edu

* We wish to thank Ellen Magenheim, Zora Pryor, Stefano Scarpetta, and F. M. Scherer for helpful comments on a draft of this essay. 


\section{SUBJECTIVE AND OBJECTIVE MEASURES OF GOVERNMENTAL REGULATION IN OECD NATIONS*}

Acting on the belief that governmental regulation has a significant impact on economic performance, this brief essay explores the aggregate extent of such regulations in various OECD nations. Any such measurement, however, runs into the immediate difficulty that "extent" has several different meanings. Nevertheless, by examining three recent attempts to quantify regulations, many of these problems are clarified so that a more rounded picture can be gained. We leave both the analysis of the actual effect of regulation (the basic data on regulation cover a period too recent for performance data to be available) and the reasons why the extent of regulation varies among counties to others.

Two different types of indicators can be employed in measuring the extent of regulation: "Objective measures" are based on the details of governmental regulation in various areas, which are assembled, quantified, and condensed. Nicoletti, Scarpetta, and Boylaud (2000) (hereafter ONSB) adopt this approach for the OECD nations. "Subjective measures" are based on surveys of business people and experts, who express their views on the extent of government regulation in various areas. Kaaufman, Kraay, and Zoldo-Lobatón (1999-a; 1999-b, 2000) (hereafter S-KKZ) and Pryor (2002-b) (hereafter S-P) adopt this approach for the OECD nations. These three studies are the empirical focus of our investigation.

Because of measurement difficulties, it is first necessary to explore a number of methodological issues, both broad and detailed. Then we present the three specific indices and, by comparing and contrasting them, show that it is possible to derive a relatively unambiguous measure which allows a perspective on the extent of government regulation in various OECD nations. 


\section{A. Methodological Issues}

$\underline{\text { 1. Broad Advantages and Disadvantages of Objective and Subjective Measures }}$

The desirable and undesirable aspects of the objective and subjective measures can be quickly summarized.

The most obvious advantage of the objective measures is that they do not greatly rely on the personal judgements of people unduly influenced by ideology, ignorance, a narrow focus on local or national regulation, or other distorting elements, such as business cycle conditions. We would expect, therefore, that this measure would be exogenous to economic developments occurring at the time the data are collected, a desirable feature if they are to be used in empirical analyses of the economic impact of regulation. Moreover, the data can be deemed to be "exact" to the extent that they are free of noise other than (hopefully small) measurement errors. ${ }^{1}$

The disadvantages of the objective measures, however, deserve note: (i) On an aggregative level they are extremely expensive to make, since they require assembling a huge data base and assistance from a great number of governments and lawyers to clarify particular points of law. Only international organizations have the funds and the clout to obtain such data and carry out such a task. $^{2}$

(ii) Such measures can, perforce, only focus on regulation on the national level. In federal countries, however, considerable regulation of economic activity is carried out by local governments and, since these are not included in the indices, they are incomplete. The may also be incomplete because particular laws and regulations are not investigated. (iii) Such measures can not indicate how the regulations are enforced and the extent to which enforcement is influenced by particular aspects of the legal system, such as the conflicts of law between different levels of government, the range and 
efficiency of regulatory enforcement, and special features such as the "adversarial legalism" found in the U.S. (Kagen 2000). ${ }^{3}$ (iv) The quantification of the regulations requires the construction and combination of various types of indexes reflecting various aspects of the laws. At this point subjective elements can enter.

The most obvious advantage of subjective measures is that the data base can be more easily assembled, since a variety of international surveys on business and expert perceptions of the extent of government regulation have been carried out in recent years. Furthermore, the answers reflect the manner in which the regulations are enforced, since restrictive regulations that are enforced simply and unambiguously may prove less of a burden than less restrictive regulations where the regulated companies are subject to lawsuits from all directions and at all levels of the judicial system. Furthermore, such survey data can cover regulation at all levels of government, depending on the ways in which the questions are asked.

The obvious disadvantage, of course, is that they rely on personal judgements which, as noted above, may be flawed and influenced by factors that are unrelated to the actual regulatory environment such as the respondents ideology or the current state of business conditions. As a result, the comparability of answers between nations is problematic, especially since many surveys ask questions about particular countries only to residents of that country. ${ }^{4}$ The variability due to unrelated factors and measurement error is likely to be larger than in objective measures, and cross-country comparisons of subjective measures should therefore account for sampling error unless very large samples of informed respondents are used.

\section{Two Specifics Problems: Coverage and Data Bases}

a. Coverage: To determine the extent to which these estimates yield the same or 
different results about the extent of government regulation, it is important to distinguish three ways of viewing the government's role in the productive sphere.

One viewpoint of government influence focuses on the type of regulation. Legal-framework

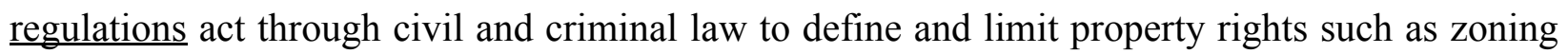
restrictions; to specify contractual obligations; to set quality standards for goods and services through tort law; and to establish conditions defining fraud, discrimination, and improper or incompetent behavior by market participants. Industry-specific regulations apply only to particular industries and act to set prices (e.g., for electricity) or maximum profit rates; to determine eligibility for entering a market (e.g., production or occupational licenses); to use a particular resource (e.g., public lands or frequencies in the electromagnetic spectrum); to provide special subsidies or taxes for particular industries; and to define prudent practices for specific types of businesses such as banks and other financial intermediaries. Administrative regulations define the ways in which business firms interact with the government. These include reporting requirements, general licensing regulations applying to all busineses, and similar activities; and general entry and exit procedures. Finally, general economic regulations deal with the specific economic activities of the economy as a whole and act to restrict pollution; to set rules for industrial relations (e.g. hiring and firing restrictions); to promulgate health and safety standards for workplaces; to limit the content of advertising; to establish antitrust policies; to determine fair business practices; and to formulate the rules for economic transactions with the rest of the world (tariffs, quantitative restrictions, and the like). All three studies under review focus primarily on administrative and general economic regulation. Nevertheless, O-NSB and S-KKZ also take into account some industry-specific regulations including barriers to foreign ownership, while these aspects are not covered in any detail in 
S-P. Moreover, both S-KKZ and S-P include certain legal framework issues pertaining to the actual enforcement of regulations. ${ }^{5}$

A second viewpoint is the extent to which the direct and indirect governmental influences on business activity are taken into account. O-NSB and S-KKZ explicitly take into account direct government intervention into business sector activities, such as public control of business enterprises, while S-P focuses exclusively on regulations that have a more indirect influence. In addition to federal regulation, two other types of indirect governmental influences on economic activity need to be considered - the methods by which regulations are enforced (including the importance of expensive lawsuits in the process), and the various regulatory measures of governments below the federal level. As noted above, both are most likely to be taken into account in the subjective measures based on the responses of business executives (S-P), less likely to be included in the evaluations of experts (which are contained in S-KKZ) and are not reflected at all in the objective measures.

A third viewpoint is the completeness of the coverage of the regulations taken into account in the calculations. For instance, both O-NSB and S-P include certain labor regulations, while S-KKZ does not. S-P also covers financial and environmental regulations, which the other two studies do not.

b. Data bases: All three of the studies discussed below focus on the 1997 - 98 period. They differ considerably in the sources of data and the way in which the data are handled.

In the last few years the OECD has assembled the requisite data base for calculating meaningful objective measures of a country's regulatory regime and it has published the results in a series of papers. ${ }^{6}$ The data-base underlying their results include around 1000 observations of 
particular aspects of central government regulations in product and labor markets in each OECD country. Of these, around 300 observations concern economy-wide regulations and the rest are industry-specific. ${ }^{7}$ Only a subset of the information contained in the database (amounting to 150 observations) was actually used in constructing the various indicators, reflecting the focus on economy-wide regulations directly affecting product market competition. Industry-specific information was used in computing economy-wide regulatory indicators either when it consistently spanned a large number of industries or it concerned industries that account for a large share of GDP (e.g. retail distribution) or it was representative of the overall regulatory stance.

O-NSB quantify the impact of various individual legal provisions into a series of indices and, using subjective weights, calculate 17 indicators for particular types of product market regulations and 18 indicators for labor market regulations related to individual hiring and dismissals. These indicators are grouped into five regulatory domains: state control, barriers to entrepreneurship, barriers to trade and investment and restrictions on permanent and temporary labor contracts. ${ }^{8}$ The indicators included in the state control and barriers to entrepreneurship domains are also divided into two broad alternative areas: administrative regulations and economic regulations.

The World Bank has also sponsored a study of objective measures of regulations in 85 countries, but these results, which cover 85 countries, just pertain to the entry of new firms. (Djankov, La Porta, Lopez-de-Silanes, and Shleifer 2002). Since our essay focuses on the entire regulatory regime, rather than a single set of regulations, we do not further discuss this extremely useful World Bank study. ${ }^{9}$

Another World Bank team (S-KKZ) combines questions from 13 different surveys, both of business people and of experts to measure the aggregate extent of regulation. They group these 
observations into four broad areas: rule of law, regulatory burden, government effectiveness and corruption, from which they derives summary indicators for each. Here, we will focus on the regulatory burden indicator, which has an obvious overlap with the O-NSB and S-P measures. This indicator includes data from 61 questions (many of which were very similar to each other) on various aspects of general economic regulations including such areas as trade and finance. In contrast to S-P and O-NSB, it includes few questions on environmental or labor regulations.

S-P combines questions from two surveys of business people and includes 33 questions which were deliberately selected to cover the foreign sector, labor markets, product markets (broadly defined, since regulations referring only to specific industries are omitted), financial markets, and the environment.

\section{Aggregation Methods and Other Gritty Statistical Details}

The three studies use different methods to combine the subindices into an overall index of government regulation. In cases where subjective weights are used, they come from the authors of the various studies. S-P uses subjective weights throughout, while both O-NSB and S-KKZ use a mix of subjective weights and statistical techniques (described below). O-NSB use these techniques mainly as a tool for reducing the dimensionality of the data, S-KKZ uses them to derive probabilistic assessments on the reliability of the cross-country comparisons.

In particular, O-NSB uses subjective weights at the lowest level of aggregation to derive their basic indicators. Thereafter, they employ a principal components analysis to derive weights for combining the various indicators into summary measures of regulation in each domain. ${ }^{10}$ Then, the summary indicators are combined into indicators of product and labor market regulation using the same statistical technique. That is, O-NSB considers the basic information on regulatory provisions 
as essentially non-stochastic and uses principal components analysis merely as a device to classify and summarize the data.

S-KKZ gives a weight to each question which is derived from the results of latent variable regressions. This study considers the replies to business surveys as random variables affected by residual "specific" variability (both within and across countries) that cannot be fully accounted for by the common factors, and estimates both the summary measures and their confidence intervals. ${ }^{11}$

S-P gives equal weight to each indicator to derive six broad areas of regulation. He then combines these in a single index, generally giving equal weight to each (excepting financial market and environmental regulations).

Aside from the statistical properties of the resulting summary indicators, both principal and unobserved components methodologies weigh each of the subindices according to the degree to which they help explain the joint variance of all the subindices among the nations in the sample. This implies that two different regulations, one of which creates a heavy burden on industry, the other which is relatively unimportant, may be given roughly the same weight if they are included in the same factor. It should be noted, however, that the O-NSB summary measures (for overall product and labor market regulations and for the five regulatory domains) remain essentially unchanged if aggregation is made by simple average of the subindices included in each of the regulatory domains. ${ }^{12}$ The subjective approach to the weighting of the subindices in S-P contains an arbitrary element and the confidence intervals of the resulting summary indicators are unknown.

\section{Final Methodological Observations}

From this description, several conclusions are immediately evident: All three aggregative measures under investigation employ quite different methodologies and data in their construction; 
all three reflect different aspects of the aggregate extent of government regulation; and all three are incomplete. If government regulation in the various countries is driven by unique economic problems in the nation, then it is highly unlikely that the three indices are correlated. This means that at the present time it is not possible to arrive at a relatively unambiguous ranking of the extent of government regulation in various OECD nations. If, by way of contrast, ideological elements play an important role in the enacting of regulations, then we would expect a relatively high correlation between these three indices and, as a result, a relatively unambiguous ranking of nations.

\section{B. Empirical Comparisons}

In order to gain perspective, it is useful to begin by comparing regulations in specific areas. Thus, we start with the product market, for which all three studies provide data. Then we turn to labor market, and finally we look at the summary measures combining both measures.

\section{$\underline{\text { 1. Product Market }}$}

Table 1 about here.

In Table 1 we present the aggregative indices for the product. In this and the other tables, the results of the three studies are standardized so that for each study, the rating of the country with the least regulation is set at zero, the rating for the country with the most regulation is set at one, and the other scores are adjusted using a linear transformation to fit between these extremes to derive a cardinal scale. We also rank the countries to provide an ordinal scale.

The comparison of the measures of product market regulation yields statistically significant correlations (at the .05 level) between all three indicators. These bivariate correlations also persist when we control for other factors. ${ }^{13}$ Such results support the notion that ideology played a key role in the enacting of regulation, rather than the pragmatic solution of problems arising from various 
types of market failures..

Some useful information is gained by examining those nations where the three estimates differ the most, using as a criterion whether the ordinal rankings differ by more than six. Comparing S-P and O-NSB studies, the former shows much greater regulation in the U.S. and Australia, and much less regulation in Finland and Switzerland. Part of these differences can be explained by the different emphasis on public ownership, which is largely ignored in the S-P measures and contributes to explain the low degree of regulation of the U.S. and the high degree of regulation of Finland in the O-NSB indicator. The relatively high regulation in the U.S. shown in the S-P index also reflects the climate of adversarial legalism in that nation, which, as noted in Section A, can only be picked up in the subjective indicators.

Comparing S-KKZ and O-NSB, the former rates Japan and Sweden as much more regulation; and Finland and Norway, as much less. These differences are difficult to explain; although they may rest, in part, on the degree of informal control that is not reflected in actual laws, especially regarding Japan where the tradition of informal "ministerial guidance" is strong. The four major differences between the rankings of S-KKZ and S-P (Canada, Sweden, and Switzerland, relatively more regulation shown in S-KKZ; U.S., relatively more regulation shown in S-P) also raise unsolved puzzles and may rest, in part, on the fact that S-KKZ included ratings of "experts" and they might not have taken the costs of adversarial legalism into account in assessing the restrictiveness of regulations, while S-P included only business executives who must daily face such costs.

In contrast to the labor market regulations, the correlations between the overall ratings of the degree of governmental regulation in the product market do not seem to hold true when one looks at the indices of regulation in more specific areas. The data in Appendix Table 1 show that the 
ratings and correlations between two of these from the O-NSB and S-P studies. For both foreign trade and administrative regulations, the correlations between the indices are much lower than for summary indicators and are not significant at conventional levels. This is hardly surprising since it is precisely in these areas where it is most difficult to measure the regulatory burden - the direct and indirect cots of administrative compliance or the existence of informal barriers to trade and capital flows, and in which the gap between formal regulation and enforcement can be largest. The O-NSB measure of administrative regulation is also considerably more detailed than the S-P measure.

\section{Labor Markets}

Only S-P and O-NSB provide separate data on labor market regulation. S-P includes seven different questions in four different areas: the perceived impact of minimum wage legislation on hiring labor, the flexibility of hiring and firing practices, the flexibility of the labor market (including adjustment of working hours in cases of change in product demand) and incentives to work (including trade-offs between social protection and work incentives). O-NSB focuses only on hiring and firing practices, but at a much greater level of detail than S-P. In particular, this former study includes the procedural inconveniences of dismissal (including delays to start notice of dismissal, definition of unfair dismissal, and difficulties of dismissal for employees with 20 years of tenure), direct costs of dismissals (including severance pay), and notice and trial period before dismissal. For temporary employment O-NSB also looks at procedures (including types of work for which temporary contracts are legal and the maximum number of successive contracts) and maximum duration of contract (including maximum cumulative duration). While the measures of O-NSB and S-P of hiring and firing practices are somewhat different, the coverage is much closer than in the case of regulation of foreign trade discussed above. 
Table 2 about here

The comparisons of labor market regulation in Table 2 show higher correlations than the comparisons of product market regulation. All of the bivariate correlations are significant at the .05 level. Of greatest importance, the correlation coefficient between the S-P and the O-NSB measures of regulation of hiring and firing is .76 , which is particularly high. We also tested whether the correlation between these measures of labor market regulation would hold if other variables were added to the equation. Similar to our experiments with the measures of product market, the relationship between the two ratings of hiring and firing practices continues to hold when we try to control for some of the factors unrelated to labor market regulation that may account for spurious cross-country variability in the S-P indicator. ${ }^{14}$

Looking at the ranking of nations and isolating those in which the rank differs by more than six in the two studies, we see that S-P finds much greater regulation of hiring and firing practices in Belgium and much less regulation in Denmark, Japan, and Portugal. These differences might be partly due to differences in coverage arising from the fact that the O-NSB study posed quite specific questions, while the S-P index focused on hiring and firing regulations in general and the answers may have been influenced by other types of labor market regulation (given the high correlation between hiring and firing regulations and overall labor market regulations). For instance, Belgium has relatively high minimum wage and unemployment benefits, compared to the rest of the OECD, while Japan has much lower; and these may influence the subjective ratings of hiring and firing regulations in general. Other differences may arise from differences in enforcement. ${ }^{15}$ For these labor market regulations, the legal climate in the U.S. does not seem to have made as much difference as in the product market. 


\section{Overall Ratings}

As noted above, while all three measures deal with product market regulations, only S-P and O-NSB cover the labor markets, and only S-P covers other areas, such as finance or environment. Nevertheless, it is instructive to compare the rankings of these overall measures because they may summarize in different ways the policy approaches followed by OECD countries.

Table 3 about here

Panel B in Table 3 shows that the bivariate correlations between the broad measures of regulation are very strong and statistically significant, being highest for the O-NSB and S-P combined measures of product and labor market regulation. Both the objective and subjective measures seem to reflect the same reality. Surprisingly, all of the correlation coefficients (excepting the S-P: P+L and S-P: Total) are roughly the same - the two subjective rankings are not much more closely related than they are with objective ranking.

The comparisons of the largest differences in the ranking reveal that the two subjective measures do not deviate systematically from the objective measure in the same way. Turning first to the labor and product markets, the S-P: $\mathrm{P}+\mathrm{L}$ and $\mathrm{O}-\mathrm{NSB}: \mathrm{P}+\mathrm{L}$ rankings are quite similar and differ by more than six ranks only for Belgium and the United States, both of which show much greater regulation in the S-P estimates. The latter undoubtedly reflects the adversarial legalism that is found in the United States. S-KKZ shows much greater regulation than O-NSB: P+L for Belgium, Canada, and Japan; and much less regulation for Netherlands and Portugal. Undoubtedly differences in coverage of the two indices account for some of these divergencies. Finally, when looking at the two subjective ratings, S-KZZ shows much greater regulation in Canada, Japan, and Switzerland and much less regulation in Norway than the S-P:P+L estimates. Again, part of these differences appear 
to be explained by differences in coverage. Interestingly, Japan and Switzerland appear to be particularly difficult countries to evaluate, since their rankings differ considerably across not only objective and subjective measures but also across the latter. For Japan, part of the problem may lie in the differences between formal regulation and informal powers exercised by various parts of the government over economic activity; for Switzerland, differences in taking account of regulation by governments below the federal level may play a role.

\section{Several Brief Conclusions}

This study looks at three quite different measures of the extent of regulation. O-NSB draws upon the largest data base of regulations; S-P, the smallest (but many of the questions used in the surveys from which the results are drawn cover several related regulations). Coverage is also different, with S-P including the broadest number of areas; although the exact coverage of S-KKZ is difficult to summarize, it does not include the labor market while O-NSB and S-P do. The aggregation approaches are also different.

Despite these differences, overall perceptions of government regulations by business leaders and experts and the objective assessment of formal regulations appear to be relatively well aligned in the areas of labor and product markets. In brief, despite the very different approaches, the results are quite similar, which suggests that ideological differences, rather than unique problems of market failures that face the individual nations, account for differences in the extent of regulation in various OECD nations.

To provide a clearer picture of these cross-country differences in regulation ithat are identified by the joint consideration of the three overall measures of regulation (S-KKZ, ONSB:P+L and S-P: Total), we employed a hierarchical cluster analysis using Ward's methodology 
to group countries according to the similarity of objective and subjective assessments. ${ }^{16}$ Two large groups of countries emerge quite clearly: a relatively "liberal" group including all English-speaking countries, as well as Denmark, Finland, the Netherlands and Switzerland; and a relatively "regulated" group including most other continental European countries and Japan. Using a less restrictive distance criterion we further isolated a group of "ultra-liberal" countries (the US, the UK, New Zealand and Ireland) and a group of "ultra-regulated" countries (France, Italy and Greece). These results provide a rigorous confirmation of our a priori expectations.

In brief, our conclusion is that all three studies point to the same economic reality, even though they draw upon quite different data and handle the data using very different statistical techniques, in detail. The next step for research is to determine more exactly how these differences in regulation influence economic performance. 
Table 1: Product Market Regulations in Some OECD Nations: Objective and Subjective Measures Panel A: Scores and Ranks

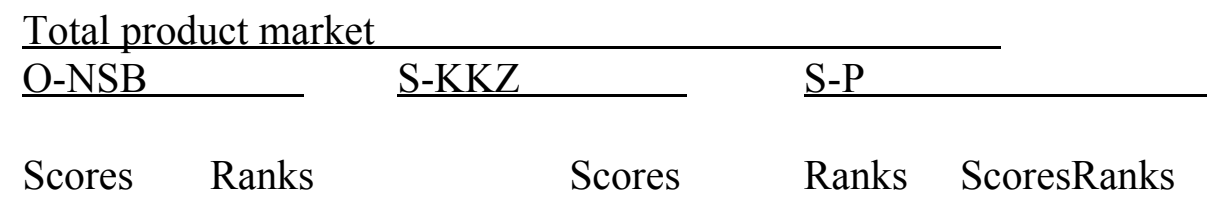

$\begin{array}{lrrrrrr}\text { Australia } & 0.24 & 3 & 0.30 & 8 & 0.40 & 12 \\ \text { Austria } & 0.49 & 8 & 0.37 & 10 & 0.39 & 11 \\ \text { Belgium } & 0.80 & 17 & 0.50 & 17 & 0.74 & 18 \\ \text { Canada } & 0.54 & 11 & 0.41 & 14 & 0.24 & 6 \\ \text { Denmark } & 0.50 & 9 & 0.19 & 7 & 0.38 & 10 \\ \text { Finland } & 0.67 & 14 & 0.08 & 5 & 0.00 & 1 \\ \text { France } & 0.88 & 18 & 0.60 & 18 & 0.78 & 19 \\ \text { Germany } & 0.52 & 10 & 0.39 & 11 & 0.31 & 7 \\ \text { Greece } & 0.97 & 20 & 0.74 & 19 & 1.00 & 21 \\ \text { Ireland } & 0.20 & 2 & 0.06 & 3 & 0.32 & 8 \\ \text { Italy } & 1.00 & 21 & 0.75 & 20 & 0.87 & 20 \\ \text { Japan } & 0.58 & 12 & 1.00 & 21 & 0.61 & 15 \\ \text { Netherlands } & 0.49 & 7 & 0.08 & 4 & 0.15 & 4 \\ \text { New Zealand } & 0.43 & 5 & 0.00 & 2 & 0.13 & 3 \\ \text { Norway } & 0.97 & 19 & 0.34 & 9 & 0.60 & 14 \\ \text { Portugal } & 0.70 & 15 & 0.39 & 12 & 0.65 & 17 \\ \text { Spain } & 0.64 & 13 & 0.42 & 15 & 0.58 & 13 \\ \text { Sweden } & 0.49 & 6 & 0.43 & 16 & 0.37 & 9 \\ \text { Switzerland } & 0.76 & 16 & 0.40 & 13 & 0.01 & 2 \\ \text { United Kingdom } & 0.00 & 1 & 0.00 & 1 & 0.16 & 5 \\ \text { United States } & 0.28 & 4 & 0.09 & 6 & 0.62 & 16\end{array}$

Panel B: Correlation coefficients (R)

$\begin{array}{llcc} & \text { O-NSB } & \text { S-KKZ } & \text { S-P } \\ \text { O-NSB } & 1.00 & .64^{*} & .55^{*} \\ \text { S-KZZ } & & 1.00 & .67^{*} \\ \text { S-P } & & & 1.00\end{array}$

Note: For S-P, the scores for product market, foreign trade sector, and general economicadministrative regulations are combined, with each given an equal weight. For S-KKZ, the overall regulation score is presented, since no labor market indicators are included. For the regressions, an asterisk designates statistical significance at the .05 level. 
Table 2: Labor Market Regulations in Some OECD Nations: Objective and Subjective Measures Panel A: Scores and Ranks

\begin{tabular}{|c|c|c|c|c|c|c|}
\hline & & & & & & \\
\hline Australia & 0.63 & 13 & 0.55 & 9 & 0.24 & 6 \\
\hline Austria & 0.68 & 16 & 0.75 & 16 & 0.61 & 12 \\
\hline Belgium & 0.91 & 19 & 0.81 & 17 & 0.53 & 9 \\
\hline Canada & 0.28 & 6 & 0.28 & 6 & 0.12 & 3 \\
\hline Denmark & 0.39 & 8 & 0.00 & 1 & 0.36 & 8 \\
\hline Finland & 0.61 & 12 & 0.58 & 10 & 0.53 & 10 \\
\hline France & 1.00 & 21 & 0.94 & 18 & 0.81 & 17 \\
\hline Germany & 0.92 & 20 & 0.98 & 20 & 0.72 & 15 \\
\hline Greece & 0.56 & 10 & 0.74 & 15 & 0.94 & 20 \\
\hline Ireland & 0.36 & 7 & 0.46 & 8 & 0.22 & 4 \\
\hline Italy & 0.86 & 17 & 1.00 & 21 & 0.87 & 19 \\
\hline Japan & 0.25 & 5 & 0.43 & 7 & 0.69 & 14 \\
\hline Netherlands & 0.68 & 15 & 0.61 & 11 & 0.61 & 11 \\
\hline New Zealand & 0.12 & 3 & 0.17 & 4 & 0.23 & 5 \\
\hline Norway & 0.65 & 14 & 0.72 & 14 & 0.76 & 16 \\
\hline Portugal & 0.51 & 9 & 0.70 & 13 & 1.00 & 21 \\
\hline Spain & 0.56 & 11 & 0.69 & 12 & 0.85 & 18 \\
\hline Sweden & 0.90 & 18 & 0.96 & 19 & 0.63 & 13 \\
\hline Switzerland & 0.00 & 1 & 0.01 & 2 & 0.30 & 7 \\
\hline United Kingdom & 0.12 & 4 & 0.14 & 3 & 0.08 & 2 \\
\hline United States & 0.11 & 2 & 0.19 & 5 & 0.00 & 1 \\
\hline
\end{tabular}

Panel B: Correlation coefficients (R)

S-P overall S-P: hiring and firing O-NSB: hiring and firing

S-P: overall

1.00

$.91^{*}$

1.00
$.64^{*}$

$.76^{*}$

1.00

O-NSB: hiring and firing

Note: For the correlation coefficients, an asterisk designates statistical significance at the .05 level. 
Table 3: Overall Business Regulations in Some OECD Nations: Objective and Subjective Measures Panel A: Scores and Ranks

\begin{tabular}{|c|c|c|c|c|c|c|c|c|}
\hline & \multirow{2}{*}{\multicolumn{2}{|c|}{$\begin{array}{l}\text { Product marke } \\
\underline{\text { S-KKZ }} \\
\underline{\text { Scores Ranks }}\end{array}$}} & \multicolumn{4}{|c|}{ Product and labor markets } & \multicolumn{2}{|c|}{$\begin{array}{l}\text { All major areas } \\
\text { S-P }\end{array}$} \\
\hline & & & $\underline{\text { Scores }}$ & Ranks & $\underline{\text { Scores }}$ & $\underline{\text { Ranks }}$ & $\underline{\text { Scores }}$ & $\underline{\text { Ranks }}$ \\
\hline Australia & 0.30 & 8 & 0.24 & 6 & 0.57 & 11 & 0.60 & 11 \\
\hline Austria & 0.37 & 10 & 0.61 & 12 & 0.60 & 12 & 0.61 & 12 \\
\hline Belgium & 0.50 & 17 & 0.53 & 9 & 0.93 & 19 & 0.98 & 20 \\
\hline Canada & 0.41 & 14 & 0.12 & 3 & 0.29 & 4 & 0.33 & 5 \\
\hline Denmark & 0.19 & 7 & 0.36 & 8 & 0.44 & 7 & 0.45 & 7 \\
\hline Finland & 0.08 & 5 & 0.53 & 10 & 0.31 & 5 & 0.27 & 4 \\
\hline France & 0.60 & 18 & 0.81 & 17 & 1.00 & 21 & 1.00 & 21 \\
\hline Germany & 0.39 & 11 & 0.72 & 15 & 0.66 & 14 & 0.70 & 15 \\
\hline Greece & 0.74 & 19 & 0.94 & 20 & 0.91 & 18 & 0.97 & 19 \\
\hline Ireland & 0.06 & 3 & 0.22 & 4 & 0.38 & 6 & 0.36 & 6 \\
\hline Italy & 0.75 & 20 & 0.87 & 19 & 0.98 & 20 & 0.97 & 18 \\
\hline Japan & 1.00 & 21 & 0.69 & 14 & 0.50 & 10 & 0.48 & 9 \\
\hline Netherlands & 0.08 & 4 & 0.61 & 11 & 0.44 & 9 & 0.46 & 8 \\
\hline New Zealand & 0.00 & 2 & 0.23 & 5 & 0.14 & 2 & 0.16 & 2 \\
\hline Norway & 0.34 & 9 & 0.76 & 16 & 0.71 & 17 & 0.73 & 17 \\
\hline Portugal & 0.39 & 12 & 1.00 & 21 & 0.67 & 15 & 0.63 & 13 \\
\hline Spain & 0.42 & 15 & 0.85 & 18 & 0.65 & 13 & 0.66 & 14 \\
\hline Sweden & 0.43 & 16 & 0.63 & 13 & 0.69 & 16 & 0.72 & 16 \\
\hline Switzerland & 0.40 & 13 & 0.30 & 7 & 0.00 & 1 & 0.00 & 1 \\
\hline United Kingdom & 0.00 & 1 & 0.08 & 2 & 0.15 & 3 & 0.23 & 3 \\
\hline United States & 0.09 & 6 & 0.00 & 1 & 0.44 & 8 & 0.51 & 10 \\
\hline
\end{tabular}

Panel B: Correlation coefficients (R)

$\begin{array}{lllll} & \text { S-KKZ } & \text { O-NSB:P }+\mathrm{L} & \text { S-P:P+L } & \text { S-P:Total } \\ \text { S-KKK } & & & & \\ \text { O-NSB: P+L } & 1.00 & 0.62^{*} & 0.61^{*} & 0.59^{*} \\ \text { S-P: P+L } & & 1.00 & 0.72^{*} & 0.68^{*} \\ \text { S-P: Total } & & & 1.00 & 0.99^{*} \\ & & & & 1.00\end{array}$

Note: $\mathrm{P}+\mathrm{L}=$ product and labor markets. The S-P calculations for all areas include, in addition to labor and product (foreign trade, general economic/administrative, and direct product markets), financial markets, and environmental regulation. For both the S-P and O-NSB indices for product and labor markets, the separate indices are combined according to the weighting methods employed in each study. In panel B, the asterisks designate statistical significance at the .05 level. 
Appendix Table 1: Two Subindices of Product Market Regulations in Some OECD Nations:

Objective and Subjective Measures

Panel A: Scores and Ranks

\begin{tabular}{|c|c|c|c|c|c|c|c|c|}
\hline & \multicolumn{4}{|c|}{ Only foreign trade } & \multicolumn{4}{|c|}{ Only general administrative regulations } \\
\hline & \multicolumn{2}{|c|}{ O-NSB } & \multicolumn{2}{|l|}{$\underline{\mathrm{S}-\mathrm{P}}$} & \multicolumn{2}{|c|}{ O-NSB } & \multicolumn{2}{|c|}{$\underline{\text { S-P }}$} \\
\hline & Scores & Ranks & Scores & Ranks & Scores & Ranks & Scores & Ranks \\
\hline Australia & 0.00 & 2 & 0.57 & 13 & 0.24 & 3 & 0.52 & 9 \\
\hline Austria & 0.06 & 5 & 0.20 & 3 & 0.44 & 11 & 0.68 & 16 \\
\hline Belgium & 0.12 & 9 & 0.66 & 16 & 0.96 & 20 & 0.81 & 18 \\
\hline Canada & 1.00 & 20 & 0.53 & 12 & 0.15 & 2 & 0.45 & 7 \\
\hline Denmark & 0.06 & 6 & 0.13 & 2 & 0.25 & 4 & 0.67 & 15 \\
\hline Finland & 0.12 & 10 & 0.49 & 11 & 0.65 & 14 & 0.00 & 1 \\
\hline France & 0.35 & 16 & 0.86 & 18 & 1.00 & 21 & 1.00 & 21 \\
\hline Germany & 0.06 & 7 & 0.26 & 4 & 0.83 & 17 & 0.58 & 12 \\
\hline Greece & 0.52 & 19 & 0.64 & 14 & 0.56 & 12 & 0.99 & 20 \\
\hline Ireland & 0.00 & 2 & 0.33 & 9 & 0.37 & 7 & 0.37 & 6 \\
\hline Italy & 0.03 & 4 & 0.66 & 15 & 0.96 & 19 & 0.93 & 19 \\
\hline Japan & 0.35 & 15 & 1.00 & 21 & 0.84 & 18 & 0.61 & 13 \\
\hline Netherlands & 0.06 & 8 & 0.00 & 1 & 0.38 & 9 & 0.32 & 4 \\
\hline New Zealand & 0.30 & 14 & 0.27 & 5 & 0.38 & 8 & 0.33 & 5 \\
\hline Norway & 1.00 & 21 & 0.69 & 17 & 0.37 & 6 & 0.64 & 14 \\
\hline Portugal & 0.37 & 17 & 0.37 & 10 & 0.40 & 10 & 0.76 & 17 \\
\hline Spain & 0.15 & 11 & 0.89 & 20 & 0.67 & 15 & 0.54 & 10 \\
\hline Sweden & 0.24 & 12 & 0.27 & 6 & 0.58 & 13 & 0.56 & 11 \\
\hline Switzerland & 0.52 & 18 & 0.28 & 7 & 0.81 & 16 & 0.19 & 2 \\
\hline United Kingdom & 0.00 & 2 & 0.30 & 8 & 0.00 & 1 & 0.22 & 3 \\
\hline United States & 0.26 & 13 & 0.89 & 19 & 0.29 & 5 & 0.49 & 8 \\
\hline \multicolumn{9}{|c|}{ B. Correlations (R) } \\
\hline & \multirow{2}{*}{\multicolumn{2}{|c|}{$\begin{array}{l}\text { O-NSB } \\
1.00\end{array}$}} & S-P & & \multirow{3}{*}{\multicolumn{2}{|c|}{$\begin{array}{l}\text { O-NSB } \\
1.00\end{array}$}} & \multicolumn{2}{|l|}{ S-P } \\
\hline O-NSB & & & \multirow{2}{*}{\multicolumn{2}{|c|}{$\begin{array}{r}.28 \\
100\end{array}$}} & & & \multirow{2}{*}{\multicolumn{2}{|c|}{$\begin{array}{r}.40 \\
1.00\end{array}$}} \\
\hline S-P & \multicolumn{2}{|l|}{1.00} & & & & & & \\
\hline
\end{tabular}

Note: For S-P, the index is labeled "general economic regulations," but the coverage is roughly the same as the "administrative regulations" of the O-NSB index. An asterisk designates statistical significance at the .05 level. 


\section{BIBLIOGRAPHY}

Djankov, Simeon, Rafael La Porta, Florencio Lopez-de-Silanes, and Andrei Schleifer. 2002. “The Regulation of Entry,” Quarterly Journal of Economics 117, No. 1 ( February, 1 - 39.

Everitt, Brian S. (1993). Cluster Analysis. New York: Halsted Press.

Everitt, Brian S. and Dunn, Graham. (1991). Applied Multivariate Data Analysis, Edward Arnold: London and Halsted Press: New York.

Kagen, Robert A. (2000). "How Much do National Styles of Law Matter," Chapter 1 in Kagen, editor. Regulatory Encounters: Multinational Corporation and American Adversarial Legalism. Berkeley: University of California Press.

Kaufmann, Daniel, Kraay, Aart, and and Zoldo-Lobatón, Pablo. (1999-a). “Aggregating Governance Indicators," www.worldbank.org/wbi/governance/.

---. (1999-b). "Governance Matters,” www.worldbank.org/wbi/governance/.

---. (2000). "Governance Matters: From Measurement to Action," Finance and Development 37, No. 2 (June).

Nicoletti, Giuseppe. (2000). "Regulation in Services: OECD Patterns and Economic Implications," OECD Economics Department Working Papers 287. Paris: OECD.

Nicoletti, Giuseppe, Scarpetta, Stefano, and Boylaud, Olivier. (1999). "Summary Indicators of Product Market Regulation with an Extension to Employment Protection Legislation,” OECD Economics Department Working Papers 237. Paris: OECD.

OECD (1999-a). OECD Employment Outlook. Paris.

OECD (1999-b). Implementing the OECD Job Strategy: Assessing Performance and Policy. Paris. OECD (2001). OECD Economic Studies, No.32, Special Issue on Regulatory Reform. Paris 
Pryor, Frederic L. 2002-a. The Future of U.S. Capitalism. New York: Cambridge University Press.

---. (2002-b). “Quantitative Notes on the Extent of Governmental Regulations in Various OECD Nations," International Journal of Industrial Organization, February forthcoming. 


\section{ENDNOTES}

1. Such errors can occur, for instance, if there are differences in the interpretation of questions by government officials responding to a questionnaire; or if the regulations of particular nations have different degrees of specificity; or if, for political reasons, the responses by governmental authorities are deliberately distorted.

2. The problem is not so great if one country is being studied over time. Moreover, certain shortcuts, such as measuring the number of pages of regulations or the governmental costs of the regulating bureaus can be used. These measures are briefly summarized in Pryor (2002-a: Chapter 11).

3. For instance, Kagen found in his interview data that although regulations may be less in the U.S. than in other countries, U.S. employers are often much more cautious about taking such particular actions because of the possibility of expensive law suits. He also found that legal costs arising from such law suits and with negotiating with regulators at various levels of government seem higher in the U.S. than in other nations. As a result, we would expect the subjective indicators of regulation in the U.S. to be much higher than the objective indicators.

4. If the subjective estimates also require the respondent to rank the relative restrictiveness of various regulations, then such results may not reflect absolute differences and, thus, cannot be compared across nations. Neither of the subjective indices discussed below contained such questions.

5. The OECD International Regulation Database and the papers in OECD (2001) provide details on specific regulations in several service industries.

6. Nicoletti, Scarpetta, and Boylaud (2000) and OECD (2001). The OECD International Regulation Database and its documentation can be accessed through the OECD Website at http://www.oecd.org/. Recent data on labor market regulations can be found in OECD (1999-a, 1999-b).

7. The database also contains observations on market and industry structure. Industry-specific data have been used in a series of supplementary studies of several utilities and service industries (OECD 2001; Nicoletti, 2000), but these will not be considered in this essay.

8. State control includes the following detailed indicators: scope of public enterprise sector, size of public enterprise sector, special voting rights, control of public enterprises by legislative bodies, use of command and control regulations (especially for particular industries, and price

controls (also for particular industries). Barriers to entrepreneurship include: licenses and permits 
system, communication and simplification of rules and procedures, administrative burden for corporations, administrative burdens for sole proprietor firms, sector specific administrative burdens, legal barriers to entry in a wide range of industries, and antitrust exemptions for state-controlled enterprises. Barriers to trade and investment include ownership barriers, discriminatory procedures, regulatory barriers, and tariffs.

9. Djankov et al. present data for five measures: the number of regulatory steps, the number of work days required to register a new firm, the costs of registering a firm as a percent of the per capita GDP, the time and cost of registering a new firm as a percent of the per capita GDP, and the absolute dollar value of time and cost of registering a new firm. In 14 out of 15 cases, these five measures are significantly correlated ( 0.05 level of significance) to the three objective and subjective measures of regulation for the entire economy discussed in this essay.

10. The sub-domains identified by principal components analysis are: public ownership, government involvement in business operation, regulatory and administrative opacity, administrative burdens on startups, barriers to competition, explicit barriers to international trade and investment and other barriers to trade.

11. On the distinction between principal and unobserved components analyses see Everitt and Dunn (1991). It should be noted that objective measures too could be considered to be random across countries to the extent that countries are drawn from a larger population of national regulatory outcomes.

12. Of course results change substantially for the indicators corresponding to the sub-domains identified by principal components analysis.

13. We tried several different types of statistical experiments. In one set of regressions, we tried to account for subjective biases by taking into account the state of the business cycle in the various countries (the gap between potential and actual output), particular biases in the English speaking world (a dummy variable of 1 if the nation is English speaking), and the subjective labor market assessments. Letting Prod-S-P stand for product market evaluations of the S-P sample; ProdO-NSB for the product market evaluations in the O-NSB sample, Lab-S-P for the labor market evaluations in the S-P sample, OG for output gap, and ES for English speaking, we calculated the following regression (standard errors are below the coefficients, an asterisk designates statistical significance at the .05 level):

$$
\begin{aligned}
& \text { Prod-S-P }=0.027+0.853 * \text { Prod-O-NSB }+0.265 \text { Lab-S-P }+0.066^{*} \mathrm{OG}+0.098 \text { ES } \mathrm{R}^{2}=0.6083 \\
& \text { (0.132) (0.204) }
\end{aligned}
$$

(0.124) $\mathrm{n}=21$

We also calculated a series of regressions holding per capita income, the logarithm of the population and ratio of foreign trade to the GDP constant, but these also continued to show a statistically significant relationship between the assessments of the extent of regulation in the three studies. 
14. Let S-P:H-F stand for the S-P index for regulation of hiring and firing; O-NSB:H-F, for $\mathrm{O}-\mathrm{NSB}$ variable for regulation of hiring and firing; Prod-S-O for the S-O rating of product market regulation; OG, for output gap; and ES for English speaking. Following the same procedures as those outlined in the previous footnote, we derived the following relationships:

$\mathrm{S}-\mathrm{P}: \mathrm{H}-\mathrm{F}=0.075+0.782 * \mathrm{O}-\mathrm{NSB}: \mathrm{H}+\mathrm{F}+0.127$ Prod-S-O $-0.002 \mathrm{OG}+0.044 \mathrm{ES} \quad \mathrm{R}^{2}=.5874$
(0.178) (0.330)
(0.240)
(0.035)
$(0.187)$
$\mathrm{n}=21$

We also calculated a series of regressions holding per capita income, the logarithm of the population and ratio of foreign trade to the GDP constant, but these also continued to show a statistically significant relationship between the assessments of the extent of regulation in hiring and firing.

15. Neither of the two studies includes a measure of the tightness in granting employment permits to foreign workers. If these were included, Switzerland would reveal a higher degree of labor market regulation.

16. For details on this clustering methodology, see Everitt (1993: 55- 90). The full results are available from the authors upon request. 